\title{
A rare case of facial neurofibroma
}

\author{
Lan Sun ${ }^{1 *}$, Lingli Tu ${ }^{1 *}$, Enqiang Liu ${ }^{2}$, Jin Zhang ${ }^{2}$, Man Wei ${ }^{1}$, Guiyu Wei ${ }^{2}$ \\ ${ }^{1}$ Department of Oncology, the People's hospital of Bishan District, Chongqing 402760, China; ${ }^{2}$ Department of Oncology, Qianjiang Central Hospital \\ of Chongqing, Chongqing 409099, China \\ *These authors contributed equally to this work.
}

Correspondence to: Dr. Enqiang Liu. Department of Oncology, Qianjiang Central Hospital of Chongqing, Chongqing 409099, China.

Email: 390323710@qq.com.

Submitted Jun 25, 2016. Accepted for publication Jul 23, 2016.

doi: 10.21037/qims.2016.07.10

View this article at: http://dx.doi.org/10.21037/qims.2016.07.10

A 62-year-old woman presented with a 6-year history of a facial tumor. Six years ago, she found a facial tumor with $1 \mathrm{~cm}$ diameter. It had an insidious onset and grown slowly. Three years ago, the tumor reached $3 \mathrm{~cm}$ in size and was removed surgically. The pathological diagnosis was neurofibroma with mucinous degeneration (Figure 1), and tumor cells were immuno-positive for vimentin (Vim), S-100, myelin basic protein (MBP), $\beta$-Catenin and neuron-specific enolase (NSE) (Figure 2). Unfortunately, recurrence occurred soon and the tumor had been developing quickly. At the time of presenting to our clinics, it measured appreciatively $15 \mathrm{~cm} \times 15 \mathrm{~cm}$ in size with a tenacious texture and a defined margin. It covers the whole face with a partial ulceration (Figure 3A). There was no discharge from the tumor. CT scan showed that the
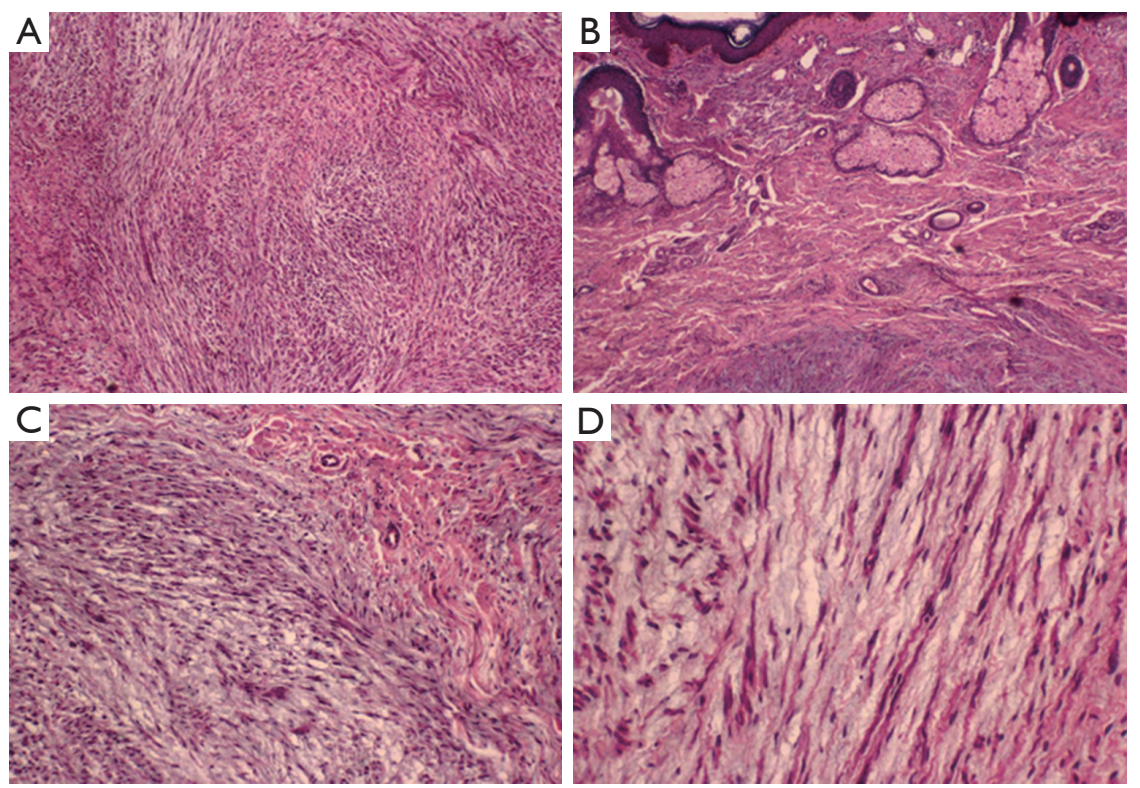

Figure 1 Histology of the neurofibroma with mucinous degeneration (H\&E staining). (A) The spindle-shaped tumor cells are in fascicular pattern (original magnification $\times 100$ ); (B) microscopically the subcutaneous mass has clear boundary $(\times 100)$; (C,D) mucinous degenerative change in loose storiform $(\mathrm{C}$ : original magnification $\times 100$, D: original magnification $\times 400)$. 

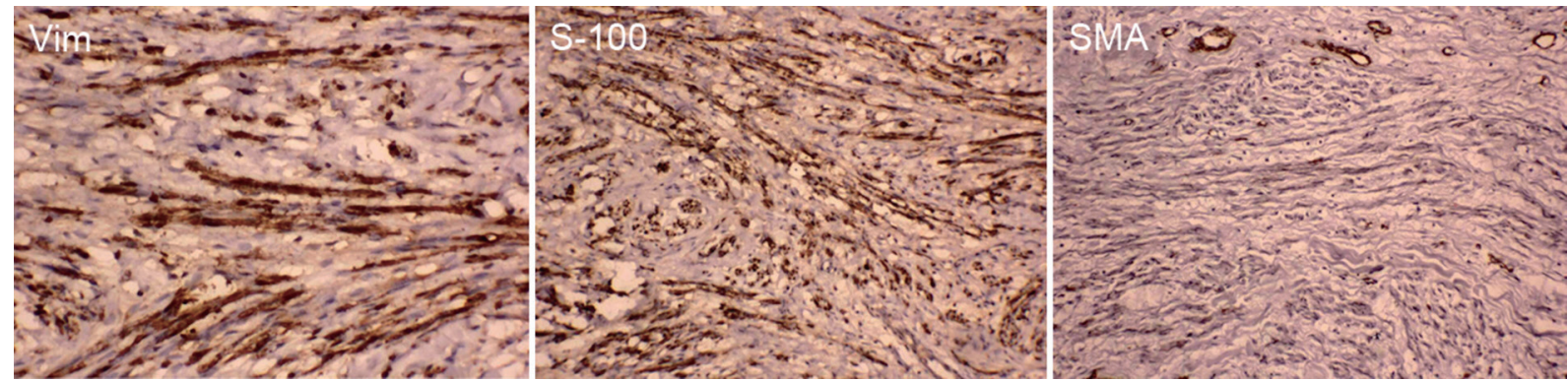

Figure 2 Tumor cells of the neurofibroma are immuno-staining positive for Vim, S-100, MBP, $\beta$-Catenin and NSE, but negative for SMA and CD57. Vim, vimentin; NSE, neuron-specific enolase; MBP, myelin basic protein; SMA, smooth muscle actin.
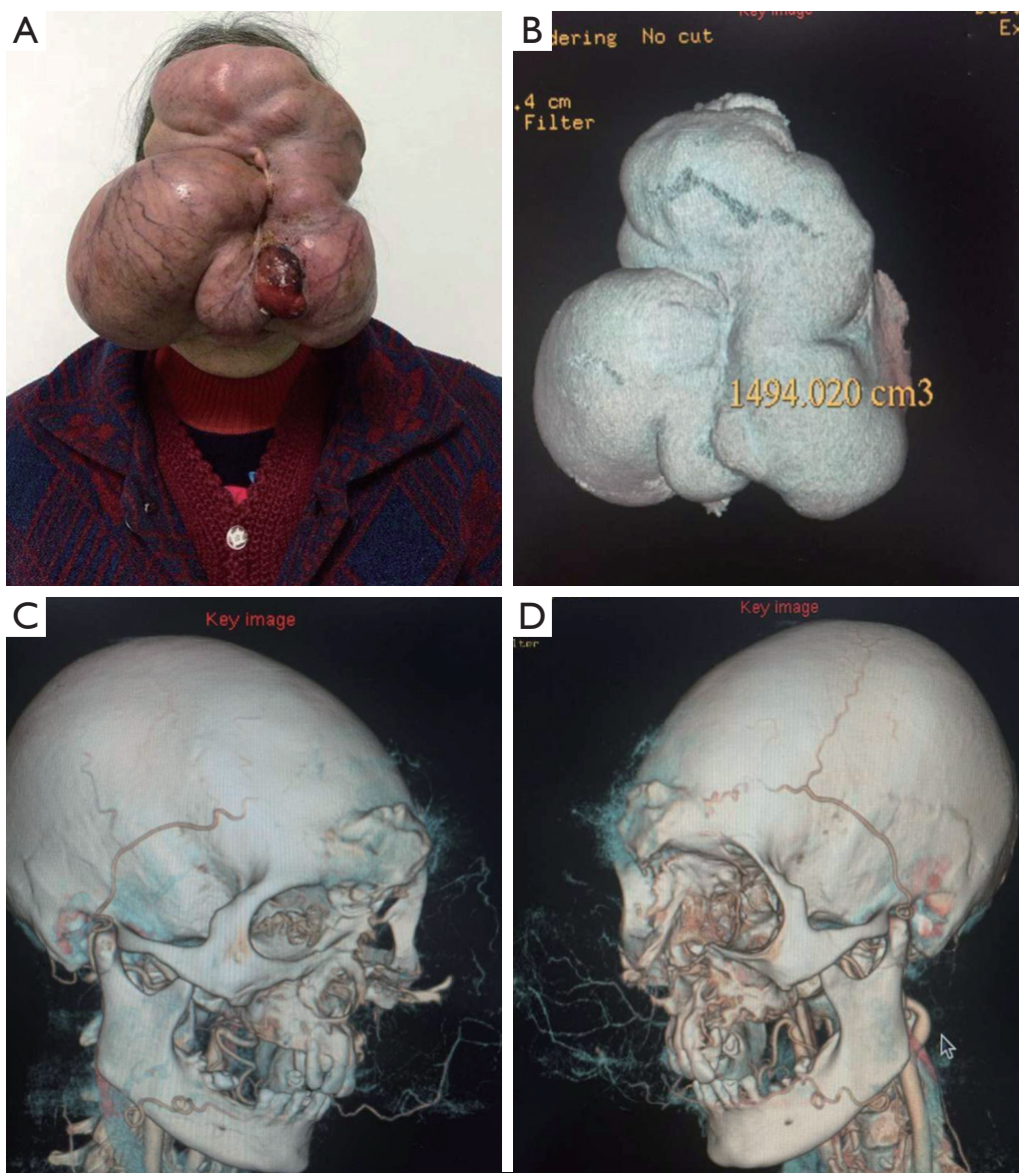

Figure 3 The facial neurofibroma has a partial ulceration (A) and the whole volume of was 1,494 $\mathrm{cm}^{3}$ (B); the tumor invaded the maxillary, ethmoid, frontal bone and nasal bone (C,D).

tumor was composed of two major sections with the whole volume of $1,494 \mathrm{~cm}^{3}$ (Figure 3B). One was derived from the left orbital cavity. The left eye is displaced and compressed. The other was derived from the right maxillofacial region that infiltrated the maxillary, ethmoid, frontal bone and nasal bone (Figure 3C,D).

Facial neurofibroma is a non-metastasizing and locally invasive tumor resulting from aberrant growth of the cells of the nerve sheath and typically occurs in the setting of neurobromatosis (1). It originates from the central aspect 
of the nerve and involves multiple fascicles composed of Schwann cells, perineurial-like cells, and fibroblasts. The involved nerves may be distorted and often totally replaced and unrecognizable (2). There is a predilection for larger peripheral nerves of the face such as our case originated from infraorbital nerves. Superficial neurofibromas are more common than the deep lesions. It is more likely to be asymmetric in distribution, extend to the skin surface in a reticular and branching pattern. It can involve rather large areas and multiple nerves. The tumor is typically painless and may go unnoticed until it become palpable or cause dysfunction of surrounding structures, such as our patient. As a result of tumor growth, adjacent bone resorption and soft tissues hyperplasia can occur. In this case, CT scan shows that the adjacent bone was invaded. Overlying skin and soft tissue may undergo hypertrophy as well as pigmentary changes. The tumor may dramatically impact the surrounding skin, soft tissues, and osseous architecture. The presence of facial neurofibromas may interfere with the nasal airway, the eyelids, vision, mastication, and lip competence, in addition to producing a cosmetic deformity (3). To our knowledge, our case is a rare type of such tumor. The primary treatment is surgery (4). Relapse is a major cause for treatment failure. Although it is high risk for face rebuilding because of the possibility of massive hemorrhage, a second surgical intervention was successfully performed for our case.

Cite this article as: Sun L, Tu L, Liu E, Zhang J, Wei M, Wei G. A rare case of facial neurofibroma. Quant Imaging Med Surg 2016;6(4):457-459. doi: 10.21037/qims.2016.07.10

\section{Acknowledgements}

Funding: This work was supported by the General Project of Chongqing Frontier and Applied Basic Research Project (No.cstc2014jcyjA10126) and the Medical project of Chongqing Health and Family Planning Commission (No.20142204).

\section{Footnote}

Conflicts of Interest: The authors have no conflicts of interest to declare.

\section{References}

1. McMonagle B, Turner J, Fagan P. Intratemporal facial neurofibroma. Otol Neurotol 2006;27:1045-6.

2. Rai A, Kumar A. Neurofibroma of facial nerve presenting as parotid mass. J Maxillofac Oral Surg 2015;14:465-8.

3. Li YX, Ma BF, Yang XM, Chai QX, Li QY. Nursing care of a patient with gigantic facial neurofibroma complicated by postoperative airway obstruction due to intraoperative massive blood loss. Chinese Journal of Nursing 2013;48:36-7.

4. Tomei KL, Gupta V, Prestigiacomo CJ, Gandhi CD. Spontaneous hemorrhage of a facial neurofibroma: endovascular embolization before surgical intervention. J Craniofac Surg 2013;24:e514-7. 